\title{
Redistricting in the Classroom: A Module for Inductive Learning
}

\author{
David Doherty, Loyola University Chicago \\ Josh Ryan, Bradley University
}

ABSTRACT We describe a hands-on teaching module on the redistricting process for use in undergraduate classes. Students engage in the process of strategically drawing district lines, which allows them to inductively understand gerrymandering and its consequences. The module also encourages students to consider the many factors that complicate efforts to identify a "fair" approach to redistricting, focusing on communities of interest. We also discuss a number of extensions to the activity and provide examples of controversial districts that may be used to illustrate various redistricting concepts.

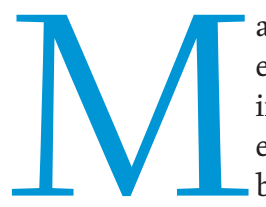

any of the concepts at the heart of political science focus on how conflicts among competing interests can and should be resolved. In our experience, students often come to class harboring expectations that there is an objectively correct way to resolve these conflicts and structure political institutions. Indeed, research suggests that much of the public believes that many of the thorniest political problems could be solved if political actors would simply eschew their own self-interest, stop responding to special interests, and do "what we all know is right" (see, e.g., Hibbing and Theiss-Morse 2002).

The process of redistricting offers a straightforward way to engage students with the ambiguity involved in establishing fair political processes as well as to familiarize them with a salient and controversial component of the American political system. In this article, we present an in-class module that is suitable for use in classes on introductory American politics, Congress, campaigns and elections, and other related topics. The module proceeds in three stages and can be implemented in a 50- to 6o-minute class period. It also may be extended in a variety of ways for longer class meetings, and we encourage instructors to customize their module depending on the needs of their particular class. The module is built around simple hands-on activities that provide a framework for students to reflect on the strategic and normative considerations that shape debates about the redistricting process.

Developing a curriculum that allows students to engage in experiential or "active" learning is important because it encourages classroom participation, promotes a deeper understanding of material,

David Doherty is an assistant professor in the department of political science at Loyola University Chicago. He can be reached at ddoherty@luc.edu. Josh Ryan is an assistant professor in the department of political science at Bradley University. He can be reached at jmryan@bradley.edu. and "give[s] life and immediacy to the subject matter" (McCarthy and Anderson 2000). Furthermore, experiential learning is particularly useful in introductory courses that encompass a broad range of material and are geared toward a wide range of student interests and backgrounds (Montgomery, Brown, and Deery 1997). Instructors have an especially important obligation in American politics courses to encourage the development of students as active citizens in American democracy who can think critically about political issues and processes (Westheimer and Kahne 2004). Other than the pedagogical advantages of hands-on learning, activities that involve participation by students rather than relying on instructorfocused lectures are enjoyable for students and instructors, making class time more gratifying for both (Baum 2002; Burmila 2010). The activities we describe herein are particularly attractive for an undergraduate class because they require few startup instructions and are sufficiently structured so that the risk of derailment due to unexpected student behavior is minimal.

The first stage of the module provides a framework for students to inductively identify the redistricting strategies used by partisan legislatures, which have led to widespread doubts about the fairness of the process. The second stage challenges the students to identify a better way to approach redistricting using their own notions of fairness. In the third stage of the module, students are encouraged to reconsider their standards for fair redistricting. This includes the consequences of redistricting processes that may lead to the fragmentation of communities of interest and a decrease in the influence of minority voting blocks in congressional elections.

The following section is a brief overview of the contemporary redistricting process and the controversies involved. We then describe each of the three stages of the class module. We conclude by discussing several potential extensions and the importance of encouraging students to think critically about issues related to representation and the fairness of political institutions and processes. 


\section{THE REDISTRICTING PROCESS AND POLITICAL}

\section{MOTIVATIONS}

Congressional district lines often are ridiculed for their peculiar shapes and the apparently cynical political principles that guide the redistricting process. During a typical redistricting cycle, the state legislature-using the normal bill-passage process-redraws districts in the year or two after a Census to account for changes in apportionment and district populations. State legislatures often engage in partisan redistricting by using sophisticated computer technology to carefully create districts composed of certain types of voters. Party identification is most often the relevant factor that determines district lines, although race also is commonly used-and may even be required under the Voting Rights Act of 1965 .

Observers and political scientists identified two major strategies that legislatures engage in when redistricting (Gelman and King 1994). The first is to use redistricting to maximize the number of party seats in the state (Cain 1985), a strategy that is more frequently used if both chambers of the legislature and the governorship are controlled by the same party (Abramowitz 1983; Niemi and Winsky 1992). The second strategy, more commonly used during periods of divided government at the state level, occurs when the legislature designs districts to protect incumbents. Both strategies are criticized as being unfair to voters because they lead to uncompetitive districts, in which voters in the partisan minority have little opportunity to elect a representative who shares their policy preferences. Moreover, uncompetitive districts may contribute to political polarization by increasing the likelihood that ideologically extreme candidates will be elected (Carson, Crespin, Finocchiaro, and Rohde 2007; but see McCarty, Poole, and Rosenthal 2009).

An alternative method of redistricting-using nonpartisan commissions-is an increasingly popular solution. Iowa, Arizona, and California are among the states that used commissions to create "fair" districts during the 2010 cycle. These reforms often are touted as an antidote to uncompetitive districts and member extremity (Brickner 2010; McDonald 2006; but see Ryan and Lyons, forthcoming). However, the complex yet imprecise phrasing of ballot initiatives designed to reform the redistricting process illustrates the array of considerations that may frustrate hopes for identifying clear principles to guide this process. ${ }^{1}$ As students discover through the stages of the module, identifying clear standards for drawing "fair" district lines is extremely difficult.

A secondary controversy centers on majority-minority districts. Empowered by the Voting Rights Act of 1965, the Department of Justice requires states to "pack" minorities into districts under certain circumstances. Although these districts promote descriptive representation (i.e., the election of minority candidates), empirical evidence suggests that they dilute the overall substantive influence of minority voters in the legislative process. As Cameron, Epstein, and O'Halloran (1996) stated, "If minority voters can influence their representative's actions without necessarily comprising a majority of the electorate, then majority-minority districts may increase the number of minority legislators but decrease the number of votes in support of minority legislation" [794].

\section{INDUCTIVE REASONING AS A ROUTE TO UNDERSTAND- ING PARTISAN REDISTRICTING STRATEGY}

The class session begins with an introduction to the basics of redistricting and reapportionment, including an explanation of why
Figure 1

Student Handout

\begin{tabular}{|c|c|c|c|c|c|c|c|}
\hline $\mathrm{D}$ & $\mathrm{D}$ & $\mathrm{D}$ & $\mathrm{R}$ & $\mathrm{R}$ & $\mathrm{R}$ & $\mathrm{R}$ & $\mathrm{R}$ \\
\hline $\mathrm{D}$ & $\mathrm{R}$ & $\mathrm{D}$ & $\mathrm{R}$ & $\mathrm{R}$ & $\mathrm{D}$ & $\mathrm{R}$ & $\mathrm{R}$ \\
\hline $\mathrm{D}$ & $\mathrm{R}$ & $\mathrm{D}$ & $\mathrm{R}$ & $\mathrm{R}$ & $\mathrm{D}$ & $\mathrm{R}$ & $\mathrm{R}$ \\
\hline $\mathrm{D}$ & $\mathrm{R}$ & $\mathrm{R}$ & $\mathrm{R}$ & $\boldsymbol{D}$ & $\boldsymbol{D}$ & $\mathrm{R}$ & $\mathrm{R}$ \\
\hline $\mathrm{D}$ & $\mathrm{D}$ & $\mathrm{D}$ & $\mathrm{R}$ & $\mathrm{D}$ & $\boldsymbol{D}$ & $\boldsymbol{D}$ & $\boldsymbol{D}$ \\
\hline $\mathrm{D}$ & $\mathrm{D}$ & $\mathrm{D}$ & $\mathrm{R}$ & $\mathrm{D}$ & $\mathrm{D}$ & $\mathrm{D}$ & $\mathrm{D}$ \\
\hline $\mathrm{R}$ & $\mathrm{R}$ & $\mathrm{R}$ & $\mathrm{R}$ & $\mathrm{R}$ & $\mathrm{D}$ & $\mathrm{D}$ & $\mathrm{D}$ \\
\hline $\mathrm{D}$ & $\mathrm{D}$ & $\mathrm{D}$ & $\mathrm{R}$ & $\mathrm{R}$ & $\mathrm{R}$ & $\mathrm{D}$ & $\mathrm{D}$ \\
\hline
\end{tabular}

There are 34 Democratic squares and 30 Republican square. Each district must contain eight contiguous squares.

redistricting is necessary due to population changes across district and state lines. We highlight the fact that redrawing district lines can have strategic implications for political parties, but we do not explain exactly how state legislatures engage in partisan gerrymandering. Students choose a partner and each pair is presented with a copy of the redistricting handout (figure 1). The handout illustrates a hypothetical state that consists of an $8 \times 8$ grid with the populations in each square or cluster assumed to be equal. Overall, the state leans slightly Democratic, with 34 blocks identified as Democratic and 30 as Republican. ${ }^{2}$

The class is divided into two groups. One group of student pairs is assigned as "Republican-controlled state legislatures," the other group as "Democratic state legislatures." Pairs of students are asked to draw eight districts of eight blocks each with the goal of maximizing gains for their party. Consistent with the process used by state legislatures, the only limitations placed on students are that the districts must be contiguous and of equal population size. This portion of the module is designed to encourage students to inductively understand the practice of "cracking and packing" often used by state legislatures (La Raja 2009). These strategies involve (1) distributing members of the opposing party across districts where they will be in the minority (i.e., cracking), and (2) creating districts composed of as many members of the opposing party as possible so as to dilute their political influence in other districts (i.e., packing).

The structure of the handout provides ways for "Democratic state legislatures" to draw district lines that yield six Democratic districts, one packed Republican district, and one toss-up district (i.e., four Republican and four Democratic "blocks"). Republican state legislatures can draw lines to yield six Republican districts and two packed Democratic districts (figures 2 and 3 ). Most students quickly grasp each gerrymandering strategy, thereby generating large party swings using the same geographical distribution of voters. We suggest that instructors allot about 10 minutes for this part of the exercise to ensure that all students have enough time to experiment with different redistricting methods.

After the exercise, we facilitate a short discussion of the strategies used to draw districts, demonstrating to students that using the same map, teams from each of the two groups generated a 
nine-seat swing between Republicans and Democrats (i.e., a fiveseat Democratic advantage in the Democratic gerrymander versus a four-seat Republican advantage in the Republican gerrymander). We then provide examples of the most seemingly egregiously gerrymandered districts in the country, in which the shape of a district is simply bizarre. The examples include Illinois's district 4 , which has been derisively referred to as the "earmuff" district; 3 Texas's district 35, which packs together liberal voters from San Antonio and Austin despite a distance of more than 80 miles between the cities; and Georgia's district 8, where a Republican gerrymander packed African American voters into another district by cutting the city of Macon nearly in half, which changed district 8 from a toss-up to a safe Republican seat. We also provide examples of targeted redistricting designed to protect incumbents-for example, carving then-state senator Barack Obama's home out of Illinois's district 1 during the 2000 redistricting cycle to prevent him from again challenging Democratic incumbent Bobby Rush in 2002.

Now that they are familiar with partisan considerations and redistricting strategies, students understand more from these maps

Figure 2

Democratic Legislature Example

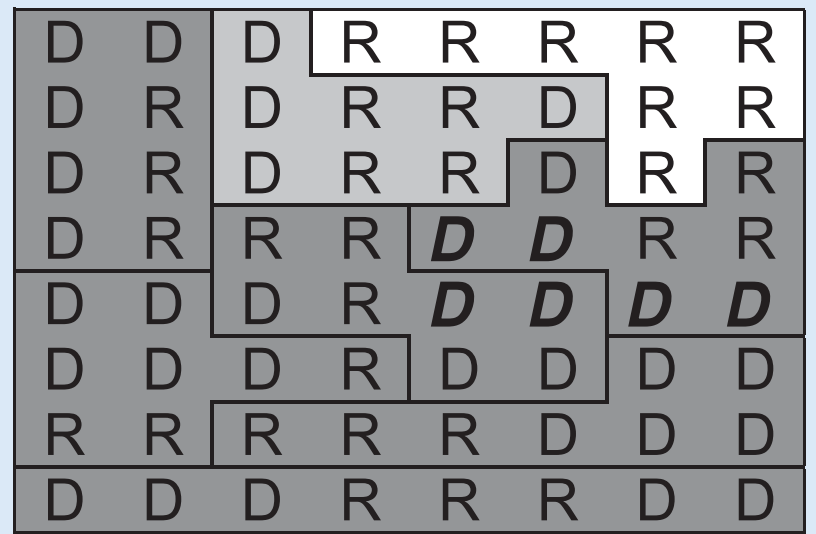

Dark districts are majority Democratic districts; white districts are majority Republican; light gray are toss-ups.

Figure 3

Republican Legislature Example

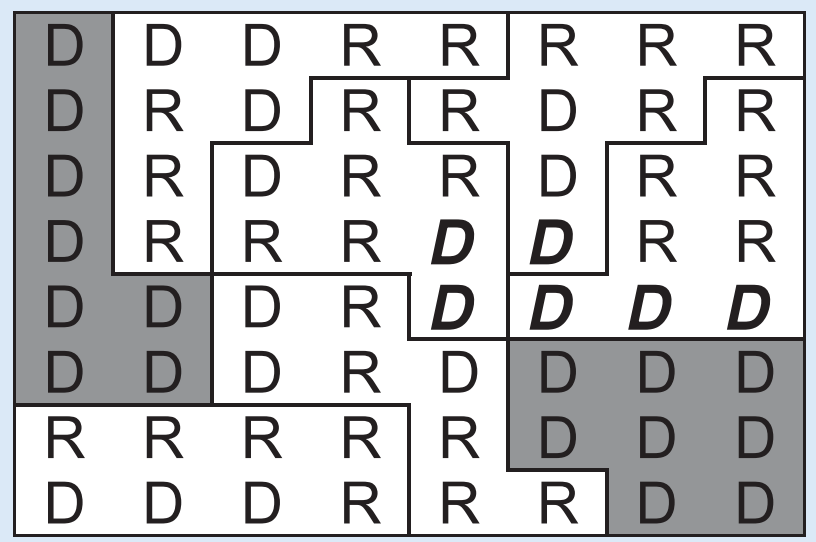

Dark districts are majority Democratic districts; white districts are majority Republican; light gray are toss-ups. than they would have otherwise-viewing actual districts connects the real world to the theoretical exercise. It has been our experience that students appreciate seeing and discussing district maps after they have thought through the partisan strategies that produce the peculiarly shaped districts.

\section{SIMULATING A NONPARTISAN COMMISSION STRATEGY}

As discussed previously, some states attempted to preclude partisan gerrymandering by establishing nonpartisan commissions to redraw district lines. Other states, including Florida and Oklahoma, passed reform measures designed to force their state legislatures to redistrict in a less partisan manner. However, other than creating geographically "compact" and contiguous districts and avoiding overtly partisan lines, it is unclear which principles should guide these commissions. Even these seemingly simple standards leave room for debate. What is the benchmark for crossing the line into "overt partisanship"? Exactly how compact must a district be?

Having established the problems commonly associated with legislature-drawn districts, the second phase of the module is designed to encourage students to consider alternative standards that may avoid the pitfalls of partisan redistricting. In this stage of the exercise, each pair of students is given a second handout and asked to think first about the goals and considerations that might guide a nonpartisan commission and then to redraw districts lines according to those standards. The instructions, mimicking the challenges faced by commissions, are intentionally vague so that each pair of students defines fairness individually. We allow another 10 minutes for this portion of the module. We also give students an extra handout for those who finish quicklyfor example, they may draw simple geometric districts (described in the following discussion) - to consider and then draw an alternative standard.

In our experience, students generally adopt one of three strategies: (1) draw as many toss-up districts as possible; (2) draw as many "packed" districts as possible; or (3) an approach that is labeled "geographic redistricting." Each strategy has a certain appeal as well as potential problems.

Many students believe that creating toss-up districts-with an equal number of Democratic and Republican blocks-is the fairest way to draw districts because it encourages competition. This sentiment reflects the opinions of many observers and political scientists (see, e.g., Carson and Crespin 2004; Fougere, Ansolabehere, and Persily 2010). Using the second copy of the handout, students can create seven toss-up districts and one Democratic district (figure 4). Although this approach is intuitively attractive, one notable flaw is that it may ignore the district-compactness requirement and the shared geographic interests of communities. The ease with which compact toss-up districts can be drawn largely depends on how closely divided a geographic area is. However, because political preferences tend to be geographically correlated, it is typically difficult to draw compact toss-up districts. As Abramowitz, Alexander, and Gunning (2006, 89) stated, "[I]f you think some of the current districts are misshapen monstrosities, try to imagine what a competitive district in the San Francisco Bay Area would look like."

Another map commonly drawn by students creates mostly packed districts (figure 5). This approach makes sense if we view fairness not as a within-district characteristic but rather as a statewide characteristic. Because of the partisan breakdown shown on the handout, 


\section{Figure 4}

\section{Maximizing Number of Competitive \\ Districts Example}

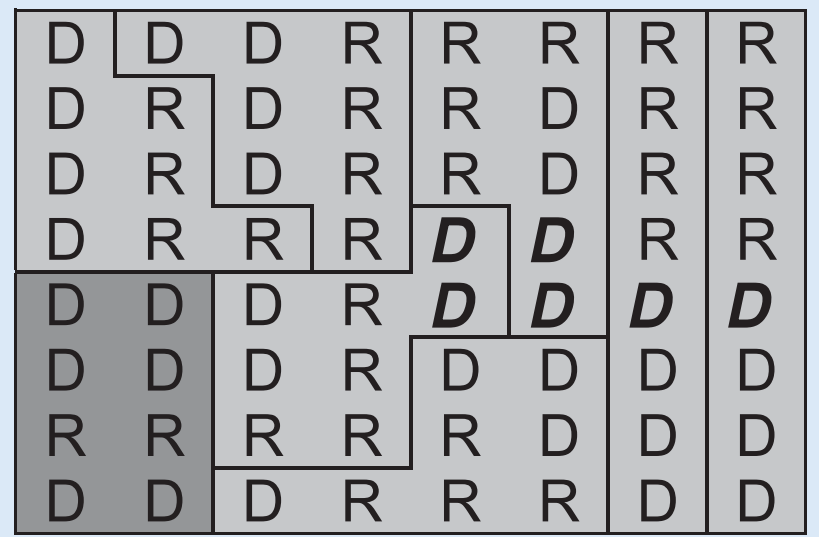

Dark districts are majority Democratic districts; white districts are majority

Republican; light gray districts are toss-ups.

students often adopt strategies that yield four Democratic and four Republican districts, or they give Democrats five solid districts. There are notable advantages to this method. Research shows that voters like to choose the winner. For example, citizens who vote for the winning presidential candidate have higher levels of political trust (Anderson and LoTempio 2002), and voting for the winner is associated with higher individual efficacy (Clarke and Acock 1989). Thus, the most normatively desirable outcome from the perspective of a democratic theorist might be to "pack" voters into districts to increase overall voter satisfaction with their representation (Brunell 2006). This approach also may result in geographically compact districts. The drawback of this approach, however, is that it leads to one of the key problems that commissions are meant to solve: uncompetitive districts.

Finally, students may conceptualize fair districts primarily in terms of being geographically compact, particularly because of the emphasis on the awkward shapes that characterize the most gerrymandered districts. Using this strategy, students block off groups of eight identically shaped rectangular districts illustrated

Figure 5

\section{Packing All Districts Example}

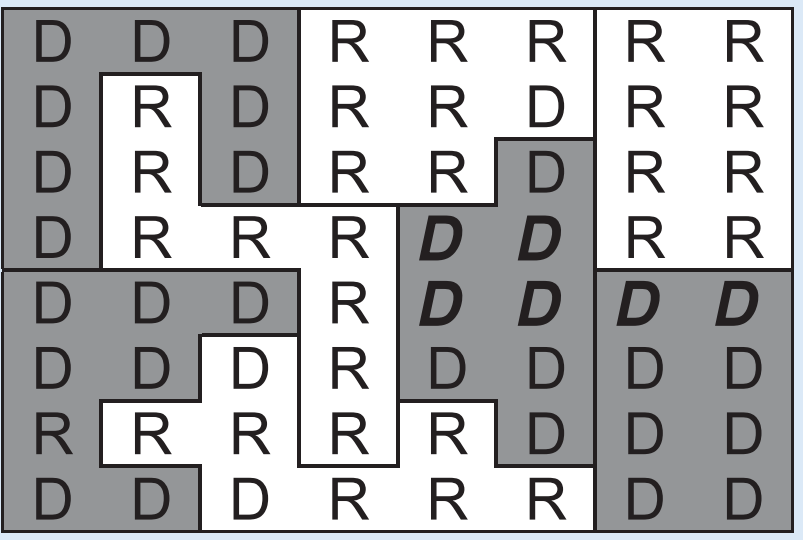

Dark districts are majority Democratic districts; white districts are majority

Republican; light gray are toss-ups.
Figure 6

Geometric Districts Example

\begin{tabular}{|ll|ll|ll|ll|}
\hline $\mathrm{D}$ & $\mathrm{D}$ & $\mathrm{D}$ & $\mathrm{R}$ & $\mathrm{R}$ & $\mathrm{R}$ & $\mathrm{R}$ & $\mathrm{R}$ \\
$\mathrm{D}$ & $\mathrm{R}$ & $\mathrm{D}$ & $\mathrm{R}$ & $\mathrm{R}$ & $\mathrm{D}$ & $\mathrm{R}$ & $\mathrm{R}$ \\
$\mathrm{D}$ & $\mathrm{R}$ & $\mathrm{D}$ & $\mathrm{R}$ & $\mathrm{R}$ & $\mathrm{D}$ & $\mathrm{R}$ & $\mathrm{R}$ \\
$\mathrm{D}$ & $\mathrm{R}$ & $\mathrm{R}$ & $\mathrm{R}$ & $\mathrm{D}$ & $\mathrm{D}$ & $\mathrm{R}$ & $\mathrm{R}$ \\
\hline $\mathrm{D}$ & $\mathrm{D}$ & $\mathrm{D}$ & $\mathrm{R}$ & $\mathrm{D}$ & $\mathrm{D}$ & $\mathrm{D}$ & $\mathrm{D}$ \\
$\mathrm{D}$ & $\mathrm{D}$ & $\mathrm{D}$ & $\mathrm{R}$ & $\mathrm{D}$ & $\mathrm{D}$ & $\mathrm{D}$ & $\mathrm{D}$ \\
$\mathrm{R}$ & $\mathrm{R}$ & $\mathrm{R}$ & $\mathrm{R}$ & $\mathrm{R}$ & $\mathrm{D}$ & $\mathrm{D}$ & $\mathrm{D}$ \\
$\mathrm{D}$ & $\mathrm{D}$ & $\mathrm{D}$ & $\mathrm{R}$ & $\mathrm{R}$ & $\mathrm{R}$ & $\mathrm{D}$ & $\mathrm{D}$ \\
\hline
\end{tabular}

Dark districts are majority Democratic districts; white districts are majority Republican; light gray districts are toss-ups.

on the worksheet (figure 6). This strategy has two primary appeals. First, in contrast with the irregularly shaped districts generated by other strategies, this approach yields simple, compact districts that look "sensible." Second, a straightforward mathematical approach can be used to create districts with equal populations that completely remove strategic considerations-and, therefore, the biases of political actors-from the process (Vickrey 1961). A suggested algorithm for drawing district lines in this way is the shortest splitline algorithm: that is, draw the shortest straight line through a state that splits the population in half; repeat this process in the newly created sections until the required number of districts is identified. Although this approach is appealing at first, it creates a new set of peculiarities in districts that are arguably problematic. We address these problems in the final section of the module.

\section{CONSIDERING COMMUNITIES OF INTEREST}

The most notable issue with the shortest-splitline algorithm approach is that it tends to divide urban areas into several districts. For example, although the algorithm draws the correct number of districts for Colorado, it also divides the city of Denver into four different districts. This separates urban voters who share similar demographic and political characteristics and draws them into districts characterized by large rural areas. ${ }^{4}$ Concerns about individual representatives being expected to represent a vast array of interests hark back to the Founding period. "Brutus" (the pen name of Robert Yates) argued in Anti-Federalist Paper No. 3 that "sixty-five men cannot be found in the United States, who hold the sentiments, possess the feelings, or are acquainted with the wants and interests of this vast country" (Yates 1787). In many cases, the shortest splitline algorithm would place representatives in a position in which they were charged with advocating for the interests of not only hundreds of thousands of constituents but also for constituents whose interests and social contexts diverge sharply. For example, the districts that split Denver include residents living in the city and the suburban areas as well as a significant rural population.

Concerns about avoiding the division of communities of interest across districts are perhaps most acute and most controversial when 
those communities are conceived of in terms of racial minorities. Many argue that to achieve demographic diversity among representatives, in states where it is possible, lines should be drawn to ensure that minority groups constitute the majority of the voting public in certain districts. These majority-minority districts are substantially more likely to elect a minority representative than a district in which a minority group accounts for less than $50 \%$ of the voting population. For example, in 2010, 26 of the 27 majority black districts were represented by a black representative. Among the 408 nonmajority black districts, only $4 \%$ (i.e., 17 districts) were represented by a black representative (only five black representatives served districts wherein less than $25 \%$ of the public is black). 5 The benefits of majority-minority districts in terms of achieving descriptive representation are further highlighted by the fact that whereas the proportion of black representatives in the House (approximately $10 \%$ ) is similar to the proportion of blacks in the general population (approximately 13\%), in the 113th Congress, there are only three black members of the US Senate and there have been only seven since Reconstruction. students to think critically about the problem and form their own opinions, and they should emphasize that debate on these issues exists precisely because there are no clear answers to these complicated questions. Considering how their own standards for fair districts might affect racial minorities results in a deeper understanding of the controversy.

At the end of the exercise, it is important to highlight the fact that different "unbiased" approaches to line drawing can lead to quite different substantive implications. We also emphasize that redistricting reforms charge commissions with creating "fair" districts, but it is almost impossible to agree on objective standards that meet the definition. Students can discuss the best way to define fairness or whether it is even possible to identify clear standards related to redistricting.

\section{STUDENT EVALUATIONS OF THE MODULE}

Ideally, we would compare student responses to this module with responses to a course on redistricting that instead relied on lecturing or other pedagogical techniques. Unfortunately, practical con-

\section{A suggested algorithm for drawing district lines in this way is the shortest splitline algorithm: that is, draw the shortest straight line through a state that splits the population in half; repeat this process in the newly created sections until the required number of districts is identified.}

At this stage of the module, we refer students to the handout on which they drew "fair" districts. The redistricting handout contains six boldfaced and italicized "D" boxes, which signify areas dominated by a racial minority. We ask students how they imagine their "fair" map might affect the way that minority is represented. We also demonstrate real-world geographic implications of trying to draw majority-minority districts by showing actual peculiarly shaped examples. Florida's $5^{\text {th }}$ district is a thin district that stretches from Jacksonville to Orlando, a distance of nearly 150 miles; however, it contains a high percentage of black voters and has been approved by the Department of Justice under the preclearance procedure that until recently was required by the Voting Rights Act. 6 Similarly, we revisit Illinois's 4th "earmuff" district and explain that this peculiarly shaped example was drawn to create a majority Hispanic district.

The concrete examples of real districts, along with the example of district lines drawn by the students, provide an excellent foundation for a discussion of whether one goal of redistricting procedures should be the creation of majority-minority districts. Specifically, we encourage students to consider how the benefits of minority groups being descriptively represented compare to the potential drawback of effectively "packing" politically like-minded minorities into a single district. In other words, what are the implications of the fact that achieving descriptive representation may degrade substantive representation? How important is descriptive representation in a democracy?

This is an important and controversial question that has generated a substantial literature (see, e.g., Cameron, Epstein, and O'Halloran 1996; Canon 1999; Lublin 1999; and Schotts 2003) but one that also is difficult for students to conceptualize when thinking abstractly. We believe that instructors should encourage their straints make doing so extremely difficult. That said, the evidence that we gathered suggests that this module stimulates learning by engaging students in thought-provoking in-class activities. Two weeks after completing the in-class module, we asked students in the classes at each of our universities to complete a survey designed to measure these outcomes.

The response was very positive. Students reported that, on average, they enjoyed the class more than a regular class period (i.e., the average student enjoyment was 5.5 out of $7 ; 1=$ student enjoyed the class much less than a normal class day and $7=$ much more than a normal class day), and that they learned more from the activity as compared to a typical lecture session (i.e., the average self-reported learning was 5.3 out of $7 ; 1=$ student learned much less than a normal class day and $7=$ much more than a normal class day). Students reported that their interest in the redistricting process increased from 3.26 prior to the exercise, on a scale of 1-7 (where 1 = not interested at all and 7 = very interested), to 5.29 after the redistricting activity. This difference in reported interest is statistically significant $(p<0.05)$. Finally, $84 \%$ of the students surveyed stated that they would like to have additional classes with similar exercises. We also asked students to explain cracking and packing strategies, and many were able to articulate clear and nuanced explanations of this strategy, even two weeks after the original exercise.

\section{SUMMARY AND EXTENSIONS}

Several extensions to the activity are possible. Instructors may choose to emphasize the campaign repercussions of redistricting, such as forcing members to run in unfamiliar territory or situations in which incumbents of the same party must run against one another.7 In additional, although the apportionment process has 
not received much scholarly attention, redistricting may be more contentious in states that lose districts. Instructors may want to use this opportunity to describe how the relative influence of northern industrial states has declined and how population shifts from the "Rust Belt" to the "Sun Belt" have led to important shifts in demographics and party coalitions. a wide-ranging discussion about these fundamental issues in American politics.

\section{ACKNOWLEDGMENT}

We are grateful to Tom McFarland for sharing an earlier version of the in-class exercise we describe here.

\section{Debates about district mapping are fundamentally questions about how citizens should be represented in republican government. Should representation promote shared interests geographically, ideologically, or otherwise, or is representation best maintained through regular, competitive elections?}

Another controversy, especially prominent after the 2012 election, is whether the overall composition of Congress reflects the preferences of voters nationwide. In 2012, Democrats received $50.5 \%$ of the total vote for all House members but only $46 \%$ of the seats. Many analysts blamed the disparity on aggressive redistricting in 2010 by Republicans in several states. It is also the case that Democratic voters are distributed less efficiently due to their heavy concentration in urban areas. ${ }^{8}$ Instructors also may choose to discuss the advantages and drawbacks of the current "winner-takes-all" system versus proportional representation.

This activity could stimulate discussions of other issues, including polls that show that Americans favor redistricting commissions despite their undemocratic nature; whether it is beneficial to artificially separate long-term congressional members from their districts through aggressive redistricting; the possible effects of term limits; and the role of redistricting in polarization. A subset of these issues may be addressed depending on available time and broader themes of the class, but each issue can be easily integrated into the module.

Debates about district mapping are fundamentally questions about how citizens should be represented in republican government. Should representation promote shared interests geographically, ideologically, or otherwise, or is representation best maintained through regular, competitive elections? Most students and observers seem to believe that partisan redistricting violates democratic norms but, as our module demonstrates, it is difficult to agree on solutions even if the redistricting body (e.g., a nonpartisan commission) does not have partisan motivations. Not only do disputes over redistricting invite questions about representation, but the process also has important implications for historical questions regarding race and fairness. Should minorities demand descriptive representation, or would these groups be better served if their influence was distributed more widely?

The exercise provides students with the opportunity to make their own judgments about gerrymandering, fairness, and racial representation while learning about an important topic. Each student may reach different a conclusion about the best approach to redistricting; however, by the end of the exercise, they all realize that there are neither perfect answers nor objective solutions. We encourage instructors to emphasize the difficulty in answering these questions and to engage with their students in

\section{NOTES}

1. For example, the Florida ballot initiative passed in 2010 reads, in part: "No apportionment plan or district shall be drawn with the intent to favor or disfavor a political party or an incumbent; and districts shall not be drawn with the intent or result of denying or abridging the equal opportunity of racial or language minorities to participate in the political process or to diminish their ability to elect representatives of their choice...districts shall be compact; and districts shall, where feasible, utilize existing political and geographical boundaries." It is virtually impossible to assess whether these standards are met objectively.

2. The map was created using Microsoft Excel. Although the partisanship of the state is not substantively important, instructors may choose to create a worksheet that reflects the partisanship or shape of their own state.

3. This district was drawn to create a majority-minority Hispanic district-a point we return to in the third section of the module.

4. Details about this approach to redistricting are published by The Center for Range Voting, which is available at http://rangevoting.org/GerryExec.html. Maps for all 50 states are available at www.rangevoting.org/SplitLR.html. Accessed by the authors on November 18, 2012.

5. Data on black representatives gathered from http://thecongressionalblackcaucus $\mathrm{com} / \mathrm{members} /$ directory/; district demographic information from factfinder2. census. gov. Analysis is based on House members with full voting privileges. Steve Cohen (a Jewish representative, serving a majority black district) and Tim Scott (a black Republican, serving a district that is approximately $20 \%$ black) were not members of the Congressional Black Caucus but they and their districts are included in the analysis. Additionally, we treat Donald Payne (elected in a special election for New Jersey's 1oth district in November 2012) as a sitting member of the House.

6. We note that at this stage of the module, instructors may want to discuss the Supreme Court decision in Shelby County v. Holder, which struck down the preclearance requirement portion of the Voting Rights Act: What kinds of redistricting strategies was that provision intended to prevent and why?

7. During the 2012 cycle, two Democrats from the Los Angeles area, Brad Sherman and Howard Berman, engaged in a particularly contentious election fight in District 3o, nearly coming to blows during a town hall event.

8. See McGhee, Eric. November 14, 2012. "Redistricting does not explain why House Democrats got a majority of the vote and a minority of the seats," The Monkey Cage. Accessed online by the authors on November 19, 2012, at http://themonkeycage.org/blog/2012/11/14/redistricting-does-not-explainwhy-house-democrats-got-a-majority-of-the-vote-and-a-minority-of-theseats.

\section{R E F E R E N C E S}

Abramowitz, Alan I. 1983. "Partisan Redistricting and the 1982 Congressional Elections.” Journal of Politics 45 (3): 767-70.

Abramowitz, Alan, Brad Alexander, and Matthew Gunning. 2006. “Don't Blame Redistricting for Uncompetitive Elections." PS: Political Science and Politics 39 (1): 87-90.

Anderson, Christopher J., and Andrew J. LoTempio. 2002. "Winning, Losing and Political Trust in America." British Journal of Political Science 32 (2):335-51.

Baum, Lawrence. 2002. "Enthusiasm in Teaching." PS: Political Science and Politics 35 (1): 87-90. 
Brickner, Benjamin. 2010. "Reading Between the Lines: Congressional and State Legislative Redistricting their Reform in Iowa, Arizona and California and Ideas for Change in New Jersey." New Brunswick, NJ: Prepared for the Eagleton Institute of Politics at Rutgers University.

Brunell, Thomas L. 2006. "Rethinking Redistricting: How Drawing Uncompetitive Districts Eliminates Gerrymanders, Enhances Representation, and Improves Attitudes toward Congress." PS: Political Science and Politics 39 (1) $77-85$.

Burmila, Edward. 2010. "Graduate Students as Independent Instructors: Seven Things to Know about Teaching Your Own Course while in Graduate School." PS: Political Science and Politics 43 (3): 557-60.

Cain, Bruce E. 1985. "Assessing the Partisan Effects of Redistricting." American Political Science Review 79: 320-333.

Cameron, Charles, David Epstein, and Sharyn O’Halloran. 1996. "Do MajorityMinority Districts Maximize Substantive Black Representation in Congress?" American Political Science Review 90 (4): 794-812.

Canon, David T. 1999. Race, Redistricting, and Representation: The Unintended Consequences of Black Majority Districts. Chicago: University of Chicago Press.

Carson, Jaime L., and Michael H. Crespin. 2004. "The Effect of State Redistricting Methods on Electoral Competition in United States House of Representative Races." State Politics and Policy Quarterly 4 (4): 455-69.

Carson, Jaime L., Michael H. Crespin, Charles J. Finocchiaro, and David W. Rohde. 2007. "Redistricting and Party Polarization in the U.S. House of Representatives." American Politics Review 35 (6): 878-904.

Clarke, Harold D., and Alan C. Acock. 1989. "National Elections and Political Attitudes: The Case of Political Efficacy." British Journal of Political Science 19 (4): $551-62$.

Fougere, Joshua, Stephen Ansolabehere, and Nathaniel Persily. 2010. "Partisanship, Public Opinion, and Redistricting." Election Law Journal 9 (4): 325-47.

Gelman, Andrew, and Gary King. 1994. "Enhancing Democracy through Legislative Redistricting." American Political Science Review 88 (3): 541-59.

Hibbing, John R., and Elizabeth Theiss-Morse. 2002. Stealth Democracy: Americans' Beliefs about How Government Should Work. New York: Cambridge University Press.
La Raja, Raymond. 2009. "Redistricting: Reading between the Lines." Annual Review of Political Science 12:203-23.

Lublin, David. 1999. "Racial Redistricting and African-American Representation: A Critique of 'Do Majority-Minority Districts Maximize Substantive Black Representation in Congress?"' The American Political Science Review 93 (1): 183-6.

McCarthy, J. Patrick, and Liam Anderson. 2000. "Active Learning Techniques Versus

Traditional Teaching Styles: Two Experiments from History and Political Science." Innovative Higher Education 24 (4): 279-94.

McCarty, Nolan, Keith T. Poole, and Howard Rosenthal. 2009. "Does Gerrymandering Cause Polarization?" American Journal of Political Science 53 (3): 666-80.

McDonald, Michael P. 2006. "Drawing the Line on District Competition." PS: Political Science and Politics 39 (1): 91-4.

Montgomery, Kathleen, Susan Brown, and Cathleen Deery. 1997. "Simulations: Using Experiential Learning to Add Relevancy and Meaning to Introductory Courses." Innovative Higher Education 21 (3): 217-29.

Niemi, Richard G., and Laura R. Winsky. 1992. "The Persistence of Partisan Redistricting Effects in Congressional Elections in the 1970 and 1980s." Journal of Politics 54 (2): 562-72.

Ryan, Josh M., and Jeffrey Lyons. Forthcoming. "The Effect of Redistricting Commissions on District Partisanship and Member Ideology." Journal of Elections, Public Opinion \& Parties.

Schotts, Kenneth W. 2003. "Does Racial Redistricting Cause Conservative Policy Outcomes? Policy Preferences of Southern Representatives in the 1980s and 1990s." Journal of Politics 65 (1): 215-26.

Vickrey, William. 1961. "On the Prevention of Gerrymandering." Political Science Quarterly 76 (1): 105-10.

Westheimer, Joel, and Joseph Kahne. 2004. "Educating the 'Good' Citizen: Political Choices and Pedagogical Goals." PS: Political Science and Politics 37 (2): 241-7.

Yates, Robert. 1787. "Anti-Federalist \#3: New Constitution Creates a National Government; Will Not Abate Foreign Influence; Dangers of Civil War and Despotism." 